PRZEGLĄD RUSYCYSTYCZNY 2020, nr 3(171)

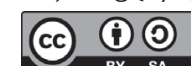

DOI $10.31261 /$ pr.7923

\author{
EDYTA ANNA FEDORUSHKOV \\ UAM Poznań \\ (D) ORCID http://orcid.org/oooo-0002-4260-5409
}

\title{
ПОЭТИКА МИФИЧЕСКОЙ ПАМЯТИ В ТВОРЧЕСТВЕ ИВАНА ЖДАНОВА
}

POETICS OF MYTHICAL MEMORY IN IVAN ZHDANOV WORKS

In the article Ivan Zhdanov poem Море, что зажато в клюве птиц, - дождъ is analized in the context of mythical memory which is interpreted as a component of mythical consciousness. As the theoretical and methodological basis served premises of culture and literature specialists primarily Olga Freidenberg's, Northrop Frye's, Vladimir Toporov's, Eleazar Meletinsky's. Our aim was to demonstrate the analogy and interdependence of co-called order of words and order of nature (by Frye).

Keywords: myth, mythical memory, mythical consciousness, Ivan Zhdanow, metarealism

Особый интерес к мифу или, шире, к мифологическому заново возродился в XX веке. Причиной тому считается духовный кризис человечества, одновременно затронувший множество сфер его жизненной деятельности. Главным потерпевшим, как можно полагать, оказался, основанный на альянсе метафизики и разума, язык, непроизвольно вербализирующий каждый акт человеческого сознания. Недоверие к языку обернулось недоверием к познавательным способностям человека, не справляющимся с неустойчивой и неоднозначной действительностью. Потеря целостной и упорядоченной картины мира заставила человечество осмыслить кризисные явления, а также заняться поисками альтернативных путей их преодоления. В области своей культурной деятельности человек решается обратиться к мифу как к начальной вехе своего сознания. Как утверждал Ролан Барт, «миф как живая память о прошлом способен изле- 
чить все недуги современности» ${ }^{1}$. В эпоху пост-хаоса, определяющей пейзаж разрушенной духовно-ценностной картины мира, миф предлагает все то, что начальное, основное и нетронутое. Чистое, заложенное на непосредственном восприятии мифологическое сознание позволяет заново изучить и освоить мир без багажа предубеждений, приобретенных во время перенесенного кризиса. Карл Густав Юнг признал миф высшей взаимосвязанной моделью запомнившихся образов человечества, моделью, к которой человек неосознанно обращается и возвращается изза необходимости объяснить и исцелить себя² ${ }^{2}$ Немалый интерес к феномену мифа, пробужденный одновременно в разных областях научной деятельности, требует, однако, особенно осторожного подхода, вытекающего все-таки из нашего объектного (внешнего) отношения к нему.

Вопрос мифологической памяти в литературе, как правило, чаще всего сводится к фабульным представлениям, почерпнутым из общеизвестных мифов древних культур: Греции, Рима, или же из космогонических мифов народов мира. Сущностью таких представлений, как можно полагать, является каркас образно-сюжетной линии. Перенесенный (более или менее осознанно) в «обновленные» бытовые обстоятельства, в результате он отображает и выявляет повторяемость человеческих поведений, являющихся, в свою очередь, основой мифологических мотивов. Однако, как пишет Елеазар Мелетинский,

сами мотивы и темы не исчерпывают мифологической модели мира как тотальной моделирующей знаковой системы. Хотя набор популярных мотивов в значительной степени определяет «физиономию» мифа [...] в принципе мотивы не являются ключом [... ] к мифологической системе. Первоначальными «кирпичиками» мифологических символических классификаций являются не мотивы, а о т н о ш е н и я в виде элементарных семантических оппозиций, в первую очередь соответствующих простейшей пространственной и чувственной ориентации человека ${ }^{3}$.

Эпика, как форма повествовательного искусства главным образом целенаправлена на мотиво-фабульное осуществление

1 Р. Барт, Мифологии, пер. С. Зенкина, Издательство им. Сабашниковых, Москва 1996, с. 283.

2 См.: К.Г. Юнг, Душа и миф. Шесть архетипов, перевод В.Наукманова, Государственная библиотека Украины для юношества, Киев 1996.

3 Е. Мелетинский, Поэтика мифа, Наука, Москва 1976, с. 230-231 (разрядка -Э.Ф.). 
художественного текста. В свою очередь лирика, основываясь на ощущении, восприятии или же, в конце концов, эмоции как главных двигателях своей художественности, оставляет в стороне заданную - с нашей точки зрения - линеарность текста. Символическое различие между эпикой и лирикой успешно может передавать разница в графической композиции обоих видов текста: эпика, как правило, подлежит горизонтальному выравниванию, лирика, в свою очередь, построена на вертикально ориентированной версификации. Данное расхождение сказывается и на различной значимости составных как повествовательного, так и поэтического произведений. Для первого центром тяжести будет, несомненно, план содержания, то есть именно фабульно ориентированное содержание текста, для второго план выражения - его форма и то, как она влияет на восприятие сознанием читателя изображенного в тексте мира.

Для канадского филолога Нортропа Фрая именно поэзия наиболее близка к первобытной мифологической форме восприятия мира. И не только по практическим соображениям, для которых-то поэзия является простейшим способом передачи оральной культуры, в которой память имеет особое значение4. По словам Фрая, поэзия сохраняет первичное употребление языка и его манеру мыслить о связях тождества, выраженных структурой «это является этим» 5 . Слова в ней воспринимаются конкретно и чувственно, как будто они сами и есть то, на что они указывают. Поэтому, как пишет Фрай, их «произнесение может иметь последствия в самом порядке природы» ${ }^{6}$.

Целью настоящей статьи является выявление непосредственной связи двух порядков - порядка природы и порядка слов в поэтическом произведении Море, что зажато в клювах птиц - дождъ..., освобождающих в памяти потенциал мифологического сознания.

Итак, обращаясь к стандартному пониманию мифа, он, по словам исследовательницы Елены Бубенцовой, «форма общественного сознания, возникшая в условиях сравнительно низкого уровня социального развития и отражающая в виде образного повествования фантастические представления о природе,

4 N. Frye, Wielki kod. Biblia i literatura, Wydawnictwo Homini, Bydgoszcz 1998, c. 55 (перевод - Э.Ф.).

5 Там же, с. 57

6 Там же, с. 42. 
обществе и личности»7. Следует заметить, что сама фантастичность представлений о мире выражает скорее современное отношение к мифу, нежели актуальное для момента его возникновения восприятие. Как пишет Ольга Фрейденберг: «мифология - выражение единственно возможного познания, которое еще не ставит вопросов о достоверности того, что познает, а потому и не добивается его» ${ }^{8}$. Поэтому для носителя мифологического сознания, как утверждает Алексей Лосев, «миф - [...] не понятие. Это есть [...] подлинная жизнь, со всеми ее надеждами и страхами»9. Следовательно, мифологическое сознание будет иметь характер неотрефлектированного и некритического мировосприятия. Такое неопосредованное отношение жизни к мифу является следствием специфического для мифологического сознания приобщения к миру: субъект тождественен объекту и не исключает его из кругозора своего собственного единичного существования. Результатом такого мировосприятия был так называемый полисемантизм, который заключался в смысловом тождестве образов, не выделяющихся тогда своими качествами, следовательно выступающих всегда в конкретной необобщенной форме ${ }^{10}$. Интересно, что, как утверждают ученые, похожим образом функционировал и сам язык. Как пишет Вадим Руднев, «в мифологическом сознании господствовал наиболее примитивный досинтаксический строй [...]: в нем слово и предложение - это одно и то же, нерасчлененные смыслы нанизываются друг на друга» ${ }^{11}$. Клод Леви-Строс определил такой способ мышления как «бриколаж», в котором всё отражается во всём. Лосев, в свою очередь, охарактеризовал мифологическое сознание как «всеобщее оборотничество ${ }^{12}$.

Вышеизложенная характеристика мифа и, в частности, мифологического сознания, на наш взгляд, получает яркое выражение в стихотворении современного алтайского поэта, Ивана

7 Е. Бубенцова, Миф в западноевропейской литературе XX века, МГУ им. А Кулешова, Могилев 2002, с. 6.

8 О. Фрейденберг, Миф и литература древности, Издательская фирма «Восточная литература» РАН, Москва 1998, с. 17.

9 А. Лосев, Диалектика мифа, http://filosof.historic.ru/books/item/foo/soo/ z0oo0933/stooo.shtml (10.03.2019).

${ }^{10}$ О. Фреденберг, Миф и литература древности..., с. 235

${ }^{11}$ В. Руднев, Словарь культуры ХХ века, Москва 1997, http://lib.ru/CULTURE/ RUDNEW/slowar.txt (15.04.2019).

${ }_{12}$ Там же. 


\section{ПОЭТИКА МИФИЧЕСКОЙ ПАМЯТИ...}

Жданова Море, что зажато в клювах птиц - дождъ. Синкретический тип мифологического мышления послужил здесь матрицей для освоения хаотичного, разрозненного образа современной действительности.

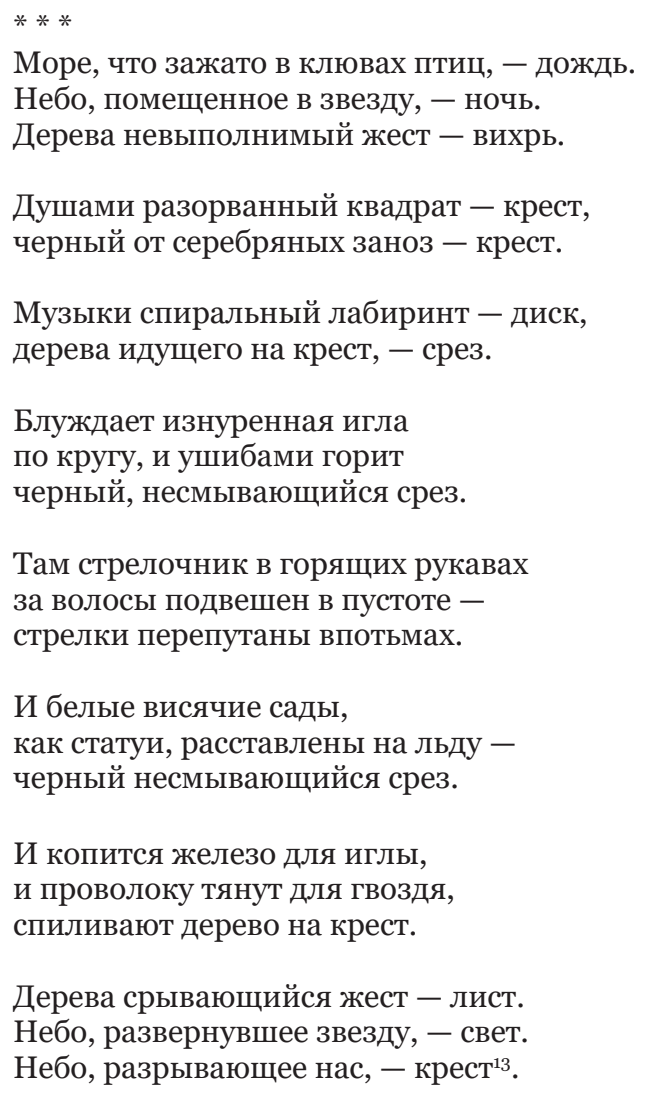

Уже довольно поверхностное прочтение текста позволяет заметить отсутствие характерной для лирики эмоциональности, выраженной при помощи отвлеченных понятий, которые выкрашивают, как правило, внутренние переживания лирического субъекта. Стихотворение, в основном, выдержано в конкретной вещественной нарицательно-причастной (реже: глагольной) конфигурации, отображающей, как можно полагать, упрощенный процесс освоения мира, в котором субъект выражает себя именно через образ этого мира. Как пишет Ольга Фрейденберг,

${ }^{13}$ И. Жданов, „Море, что зажато в клювах птиц...” // его же, Воздух и ветер. Сочинения и фотографии, «Наука», Москва 2005, с. 77. 
отделение субъекта от объекта было длительным процессом. [...] Сперва оно носило форму восприятия субъекта в категориях объекта и перенесения объекта на субъект. [...] Сознание долго воспринимало себя сквозь «не-я». [...] Субъективное могло быть понято только через объективное. [...] Сквозь объективное рождался человек ${ }^{14}$.

Освоение мира невыраженным лирическим субъектом принимает форму континуально-циклического круговорота, характерного для мифологического сознания: цепь поочередно появляющихся образов намечает линию, описывающую круг. Именно такую линию прослеживает глазами наблюдающий субъект (читатель). Внимания заслуживает синтаксический строй первых строк стихотворения: наблюдаемая линейность возникающих образов не внушает, что их свойством является временная протяженность, а как раз наоборот, наводит на мысль о некоторой вневременности или же одновременности видимого. Данная неопределенность связана, как можно полагать, с особой трактовкой времени мифологическим мышлением. Как пишет Владимир Топоров,

в мифопоэтическом хронотопе время сгущается и становится формой пространства (оно «спациализуется» и тем самым как бы выводится во вне, откладывается, экстенсифицируется), его новым («четвертым») измерением. Пространство же, напротив, «заражается» внутренне интенсивными свойствами времени („темпорализация” пространства), втягивается в его движение, становится неотъемлемо укорененным в разворачивающемся во времени мифе $\mathrm{e}^{15}$.

Темпорализацией пространства обделены, как можно полагать, промежуточные звенья начальных строк стихотворения («зажато в клювах птиц», «помещенное в звезду», «невыполнимый жест»). Выраженные в форме причастных оборотов, они «спациализируются» (ввиду смены своей глагольной темпоральности) на признак предмета. Как замечает Топоров,

архаическое понимание пространства-времени заключается в том, что оно не предшествует вещам, его заполняющим, в наоборот, конституируется ими. [...] пространственно-временной континуум связан с вещественным наполнением, т.е. всем тем, что так или иначе 'организует' пространство, собирает его, сплачивает, укореняет в едином центре (язык пространства, сжатого до точки) ${ }^{16}$.

14 О. Фрейденберг, Миф и литература древности..., с. 237.

${ }_{15}$ В. Топоров, Пространство и текст // того же, Текст: семантика и культура, издательство Наука, Москва 1983, с. 232.

${ }_{16}$ Там же, с. 234. 
Нельзя забывать, что мифологическое пространство не самоцельно. Его конституирование принадлежит мифологическому сознанию: осваивая мир, человек одновременно творит его, придает ему целесообразность и постепенно выводит из хаоса. Итак, из беспредельного моря формируются капли дождя, а необозримый дневной небосвод, сжатый до маленькой точки звезды, «раскрывает», декомпрессирует ночь. Немаловажную роль играют здесь вышеупомянутые посредствующие звенья, названные Михаилом Эпштейном «промежуточными понятиями», которые объединяют «удаленные предметные области» ${ }^{17}$, т.е. море - дождь, небо - ночь, и обеспечивают их взаимопричастность, укрытую взаимофункциональность. Однако, прежде всего, их введение наглядно выявляет «наивный», как мы бы сказали сегодня, механизм познания мира мифологическим сознанием. Как пишет Василий Пивоев,

чувственное познание не в состоянии отделить существенное от несущественного, закономерное от случайного, не может выявить сущностные отношения между предметами и явлениями, а только феномены ${ }^{18}$.

Для первобытного человека, как можно полагать, единственным достоверным путем, которым вода могла попасть в верхние слои атмосферы и видоизмениться в дождь, является подоблачный путь, преодолеваемый птицами. Также угасание дневного неба предположительно объяснялось его «помещением» в единственную видимую точку - звезду - на фоне непроглядной ночи. Мифологическое восприятие мира опирается, таким образом, на непосредственное отражение действительности, которое и является чистейшим способом ее познания. Дополняющим элементом осваиваемого человеком мира является образ дерева, выступающего, как можно полагать, от имени земли, стихии, породившей человека и приобщившей его к жизни.

Итак, три первые строки стихотворения, во-первых, демонстрируют мифологический способ познания природного мира, во-вторых, являются своего рода вводным алгоритмом для восприятия уже не такого однозначного мира, представленного в последующих строках. Другими словами, мифологическое

${ }_{17}$ М. Эпштейн, Поэзия и сверхпоэзия. О многообразии творческих миров, Издательство Азбука, Санкт-Петербург 2016, с. 168.

${ }_{18}$ В. Пивоев, Мифологическое сознание какспособосвоениямира, Издательство „Карелия”, Петрозаводск 1991, с. 25. 
сознание позволяет подойти непосредственно к разобщенному миру и повторно объединить и упорядочить его погруженные в хаос элементы.

Продолжением образа дерева можно считать образ креста, постепенно развертывающийся в следующей строке. Ему предшествует квадрат, относящийся к геометрическому пространству и тяготеющий к его (пространства) объективизации и отделению от познающего субъекта. Геометрической трактовке пространства, как пишет Топоров, свойственна установка на устранение из него качественных различий, любых признаков одухотворенности ${ }^{19}$. Эту научную последовательность упраздняет, однако, порядок мифологического мышления, преобразовывающий или, вернее, одухотворяющий абстрактную фигуру в крест. Наряду с квадратом появляется образ диска - пластинки, звуковая дорожка которой переходит в образ колец срезанного дерева. Однако поскольку профиль пластинки иллюстрирует спиралевидный и все-таки линейный образ действительности, постольку структура слоёв дерева - годовых колец, как указателей его возраста, манифестирует расширяющуюся кольцевую повторяемость. Фигура кольца как символ целостности служит также эмблемой вечно возвращающегося, следовательно, возрождающегося времени ${ }^{20}$.

Переплетающиеся и воспринимаемые сквозь призму мифологического сознания образы - дерево, квадрат, крест, диск, срез - выстраивают пространство, состоящее из феноменов деформированного мира. Заметно, что переход между ними совершается не по принципу их конвенциональной близости, а по принципу их фигурального подобия. Можно полагать, что наблюдающий субъект выстраивает инстинктивную, неопосредованную и неограниченную конвенцией современного мира цепочку ассоциаций, напоминающую непроизвольно подбрасываемый подсознанием ряд образов, характерных для сна. Как пишет Вячеслав Иванов, «характер ограничений, снимаемых во сне, близок типу ограничений, не играющих роли для мифологического мышления ${ }^{21}$. На фигуральном сходстве заложены также образы занозы, иглы, проволоки и гвоздя. Наложение об-

19 В. Топоров, Пространство и текст..., с. 230.

${ }^{20}$ Х.Э. Керлот, Словарь символов, пер. Н. Богун, «REFL-book», Москва 1994, c. 255.

${ }^{21}$ Вяч. Иванов, Знаковая система бессознательного как семиотическая проблема // его же Избранные труды по семиотике и истории культуры, T.IV, издательство???, Москва 2007, с. 237. 
разов друг на друга, как можно полагать, ведет к образованию фабулы или, вернее, сюжета. Заметно, что с четвертой строфы стихотворения несколько меняется синтаксическая структура строк. Можно сказать, что строки эти тяготеют к фабульности: номинативный режим, характерный для первых строф, меняется режимом повествовательным: вводятся первые глагольные формы, заметен анжамбеман, нарушающий (сбивающий) равномерность и синтаксическую ритмизированность предыдущих строк, неоднократно употребленная анафора в виде союза «и» придает очередным строкам форму события, развертывающегося все динамичнее и динамичнее. Как пишет Фрейденбегр, «сюжет имел стадию долитературную и даже дословесную, когда его морфология совпадала с морфологией действия, вещи, кинетической речи, мира действующих лиц, с которыми он был слит» ${ }^{22}$. Таким образом выстроенный сюжет не подчинен воли потенциального повествователя, а подчинен воли образов, навязывающих «свою фабулу» сознанию субъекта (что до сих пор «делает» с нами сон). Власть субъекта над фабулой, тем самым, редуцирована к его феноменальному опыту - феноменальной памяти: предметам и явлениям, которыми располагает его сознание. Этот нарративный ход стихотворения прекращается в последней строфе, являющейся, если так можно выразиться, с одной стороны, синтаксическим повторением, с другой - парадигматическим перевоплощением первой строфы стихотворения. Начатый акт освоения мира получает в конце стихотворения кольцевое дополнение и расширение. Впервые появляется выраженная форма лирического субъекта в виде местоимения «нас». Перефразируя слова Ольги Фрейденберг, можно сказать, что сквозь объективное - то есть объекты окружающего мира, и «родился» человек, который впервые осознает свое активное участие в происходящих событиях. Существенно то, что, подменяя образы птиц или звезды, подобно им, человек служит природным «посредствующим звеном» в акте осваивания (сотворения) мира, сознательно встраивая себя в мир природы и придавая ей смысл. Тем самым природа и человек взаимодополняют друг друга. Целостность мира, его природная закономерность восстанавливается именно благодаря особой стимуляции генетической оболочки мифа.

${ }^{22}$ О. Фрейденберг, Поэтика сюжета и жанра, «Лабиринт», Москва 1997, c. 222. 


\section{EDYTA ANNA FEDORUSHKOV}

\section{REFERENCES}

Barthes, Roland. Mifologii. Transl. Zenkin, Sergey. Moskva: Izdatel'stvo im. Sabashnikovykh, 1996 [Барт Роланд, Мифологии. Перев. Зенкин, Сергей. Москва: Издательство им. Сабашниковых, 1996].

Bubencova, Elena. Mifoligizm v zapadnoevropejskoj literature XX veka. Mogilev: MGU im. A. Kuleshova, 2002 [Бубенцова, Елена. Мифологизм в западноевропейской литературе XX века. Могилев: МГУ им. А. Кулешова, 2002].

Epshteyn, Mikhail. Poeziya i sverkhpoeziya. O mnogoobrazii tvorcheskikh mirov. Sankt-Peterburg: Izdatel'stvo Azbuka, 2016 [Эпштейн, Михаил. Поэзия и сверхпоэзия. О многообразии творческих миров. Санкт-Петербург: Издательство Азбука, 2016].

Freydenberg, Ol'ga. Mif i literatura drevnosti. Moskva: Izdatel'skaya firma "Vostochnaya literatura" RAN, 1998 [Фрейденберг, Ольга. Миф и литература древности. Москва: Издательская фирма “Восточная литература” РАН, 1998].

Freydenberg, Ol'ga. Poetika syuzheta i zhanra. Moskva: “Labirint”, 1997 [Фрейденберг, Ольга. Поэтика сюжета и жанра. Москва: “Лабиринт”, 1997].

Frye, Northrop. Wielki kod. Biblia i literatura, Transl. Fulinska, Agnieszka. Bydgoszcz: Wydawnictwo Homini 1998.

Ivanov, Vyacheslav. “Znakovaya sistema bessoznatel'nogo kak semioticheskaya problema." Izbrannyye trudy po semiotike i istorii kul'tury. T. IV. Moskva: Yazyki slavyanskoy kul'tury, 2007 [Иванов, Вячеслав. “Знаковая система бессознательного как семиотическая проблема.” Избранные труды по семиотике и истории культуры. T. IV. Москва: Языки славянской культуры, 2007].

Kerlot, Khuan Eduardo. Slovar' simvolov. Transl. Bogun, N. et al. Moskva: «REFLbook», 1994 [Керлот, Хуан Эдуардо. Словарь символов. Перев. Богун, Н. и др. Москва: «REFL-book», 1994].

Losev, Aleksey. Dialektika mifa. <http://filosof.historic.ru/books/item/foo/soo/ zoooo933/stooo.shtml> [Лосев, Алексей. Диалектика мифа. <http://filosof. historic.ru/books/item/foo/soo/zoooog33/stooo.shtml>].

Meletinskiy, Yeleazar. Poetika mifa. Moskva: Nauka, 1976 [Мелетинский, Елеазар. Поэтика мифа. Москва: Наука, 1976].

Rudnev, Vadim. Slovar' kul'tury XX veka. Moskva: AGAF, 1997, <http://lib.ru/ CULTURE/RUDNEW/slowar.txt> [Руднев, Вадим. Словарь культуры XX века. Москва: АГАФ, 1997, <http://lib.ru/CULTURE/RUDNEW/slowar.txt>].

Pivoev, Vasiliy. Mifologicheskoye soznaniye kak sposob osvoyeniya mira. Petrozavodsk: Izdatel'stvo "Kareliya”, 1991 [Пивоев, Василий. Мифологическое сознание как способ освоения мира. Петрозаводск: Издательство “Карелия", 1991].

Toporov, Vladimir. "Prostranstvo i tekst." Tekst: semantika i struktura. Moskva: izdatel'stwo „Nauka”, 1983. [Топоров, Владимир. "Пространство и текст” Текст: семантика и структура. Москва: Издательство «Наука», 1983].

Yung, Karl Gustav. Dusha i mif. Shest' arkhetipov. Transl. Naukmanov, V. Kiev: Gosudarstvennaya biblioteka Ukrainy dlya yunoshestva, 1996 [Юнг, Карл Густав. Душа и миф. Шесть архетипов. Перев. Наукманов, В. Киев: Государственная библиотека Украины для юношества, 1996].

Zhdanov, Ivan. "More, chto zazhato v klyuvakh ptits...” Vozdukh i veter sochineniya ifotografii. Moskva: Nauka, 2005 [Жданов, Иван. “Море, что зажато в клювах птиц...” Воздух и ветер. Сочинения и фотографии. Москва: Наука, 2005]. 